\title{
A imprensa paulista na década de 1870: locus de divulgação e circulação de impressos
}

\section{The press in São Paulo in the 1870's: locus of promotion and circulation of printed works}

\author{
Célia Regina da Silveira*
}

\begin{abstract}
Resumo
Este artigo tem por objetivo refletir sobre a circulação de livros e impressos na Província de São Paulo com base na discussão realizada nos e pelos próprios periódicos acerca do contexto da imprensa e dos leitores na Província de São Paulo, no decênio de 1870. Afinal, eram os jornais um dos principais suportes de veiculação da propaganda dos livros e impressos, isto é, constituíam-se em um dos meios que tornavam possível dar a conhecer o universo do repertório de impressos disponíveis para o público leitor. Junto a esse propósito, procurarse-á, ainda que de forma parcial, mostrar quem eram os livreiros e agentes de livrarias que compareciam nos jornais pesquisados, a fim de reunir elementos que permitam mostrar como se davam as conexões do comércio de impressos na Província de São Paulo, na década mencionada.
\end{abstract}

Palavras-chave: Jornais Paulistas; Circulação de Impressos; Mediadores Culturais.

\begin{abstract}
This paper aims to consider the circulation of books and printed works in the Province of São Paulo based on the discussion which occurred in (and by) the newspapers concerning the context of the press and the readers in the Province of São Paulo, during the decade of 1870. After all, the newspapers were one of the main advertising vehicles of books and printed works, that is to say, they were one of the ways that made it possible to know the universe of the repertoire of printed works available to the readers. Besides this purpose, we seek to show, although partially, who were the booksellers and bookstores agents who appeared in the surveyed newspapers, in order to gather evidence of how the trade connections of printed works happened in the Province of São Paulo, in the mentioned decade.

Keywords: Newspapers of São Paulo; Circulation of Printed Works; Cultural Mediators.

\footnotetext{
"Pós-doutoranda no Programa de Pós-Graduação em História Social da Universidade Estadual Paulista (UNESP), campus de Assis. Professora Associada do Departamento de História da Universidade Estadual de Londrina.E-mail: csilveira@uel.br
} 


\section{“Civilização da escrita": livro, jornal, biblioteca}

Nas últimas décadas os impressos (livros, periódicos, revistas, folhetos etc.) têm ocupado um lugar de destaque como objeto de estudo entre os historiadores, tanto estrangeiros quanto nacionais. Fruto de muitas reflexões desde o século XIX, a história dos impressos, irremediavelmente associada à da leitura, impôs-se como um campo específico de estudos na historiografia. Um dos trabalhos pioneiros foi L'apparition du livre, do historiador francês Lucien Febvre, escrito em parceria com Henri-Jean Martin e publicado em 1958. ${ }^{1}$ Tornou-se um clássico da história do livro e foi inserido na tradição dos estudos da história social quantitativa da chamada Escola dos Annales, que privilegiou um enfoque de longa duração no tratamento da produção e do consumo dos livros, sem se deter em detalhes da bibliografia. Antes, preocuparam-se em apresentar um panorama do mundo da impressão e do comércio dos livros na Europa, particularmente na França, fundamentados em inventários, testamentos e catálogos de feiras, lançando assim as bases para o estudo da leitura e do livro como bens de consumo, ${ }^{2}$ que nas décadas seguintes constituiria mais um campo de investigação na historiografia, como uma das variantes da História Cultural.

Segundo assinala o historiador norte-americano Robert Darnton - também um estudioso da história do livro, especialmente na França do Antigo Regime -, o exemplo de abordagem socioeconômica da Escola dos Annales na investigação histórica das obras escritas difundiu-se, a partir da década de 1960, por toda a Europa e pelos Estados Unidos. Num breve período de 20 anos, os estudos historiográficos em questão se tornaram "um campo de estudo rico e diversificado", ensejando a criação de periódicos e centros de estudos, bem como a divulgação de "suas pesquisas em escala internacional". ${ }^{3}$ Essas iniciativas individuais e conjuntas de pesquisadores de várias nacionalidades proporcionaram outras motivações historiográficas e metodológicas,

\footnotetext{
${ }^{1}$ FEBVRE, Lucien; MARTIN, HENRI-Jean. 0 aparecimento do livro. São Paulo: Edunesp/Hucitec, 1992. ${ }^{2}$ Ibidem.

${ }^{3}$ DARNTON, Robert. 0 beijo de Lamourette: mídia, cultura e revolução. São Paulo: Companhia das Letras, 2010, p. 123. Ainda segundo o autor, a tradição dos Annales aplicada à história do livro veio a fortalecer as tradições relativas ao estudo do tema em alguns países: "[...] como o estudo da recepção na Alemanha e a história da imprensa na Grã-Bretanha. [...] Criaram novos periódicos - Plublishing History, Bibliography Newsletter, Nouvelles du livre ancien, Revue française d'historie du livre (nova série), Buchhandelsgeschichte e Wolfenbutteler Notizen zur Buchgeschte. Fundaram novos centros de estudo - O Institut d'Étude du Livre em Paris, o Arbeitskreis fur Geschichte des Buchwesens em Wolfenbuttel, o Center for the Book na Biblioteca do Congresso. Colóquios especiais - em Genebra, Paris, Boston, Worcester, Wolfenbuttel e Atenas, para citar apenas alguns que se realizaram no final dos anos 1970.", p. 124.
} 
demarcadas por novas fontes e recortes temáticos, além de temporalidades mais curtas, para o tratamento da história do livro e da leitura, sem deixar de recompor o universo livresco num horizonte mais amplo do sistema de transmissão das ideias - o qual envolve a produção, a circulação e as práticas de leitura. ${ }^{4}$

Ao realizar, em 2004, uma retrospectiva dos últimos 50 anos da história do livro, Jean-Yves Mollier ressaltou a ideia de que Lucien Febvre - um dos inspiradores da história do livro -, 20 anos antes de publicar L'apparition du livre, propunha a noção de "civilização da escrita", compreendendo o livro, ao lado do jornal e da biblioteca, como um dos vetores da cultura escrita em La Civilisation écrite: le livre, les journaux, les bibliothèques. Para Mollier, "[...] essa ordem não foi escolhida ao acaso, de modo que o livro se inscrevia como o elemento fundador de uma civilização do escrito, interditando por certo qualquer veleidade de pensar uma 'civilização do jornal' ou 'do livro' autônoma”. ${ }^{5}$

Não obstante a posição de Fevbre, nos anos 1930, em favor da não separação da história do livro e da imprensa, vistos como componentes de uma "civilização da escrita" - ferramentas de comunicação entre os homens -, as citadas vertentes historiográficas traçaram percursos específicos em cada país, como mencionado por Robert Darnton (2010). Na Itália e na Espanha, informa Mollier, recentemente foram criadas as cadeiras da história do livro e do jornal em várias universidades, distintamente do caso da França, onde as duas histórias caminham de maneira paralela, fato que ele atribui a "uma incapacidade congênita de praticar a pesquisa coletiva". ${ }^{6} \mathrm{O}$ citado estudioso posiciona-se como um defensor do plano de Lucien Febvre: o da "combinação da história do livro e da imprensa".

Mesmo considerando que o livro e o jornal são suportes materiais distintos e que, por isso, ensejam também formas distintas de leitura, requerendo assim tratamentos específicos, ambos fazem parte de uma "civilização escrita", que propõe uma questão em comum para os pesquisadores (sejam os dos livros, sejam os dos jornais, ou de qualquer outro tipo de escrita menos convencional): a forma como se realiza a transmissão das ideias, suas

\footnotetext{
${ }^{4}$ Cf. ibidem, p. 122-150.

${ }^{5}$ MOLLIER, Jean-Yves. A história do livro, da edição e da leitura: um balanço de 50 anos de trabalho. Texto apresentado no I Seminário Brasileiro sobre o livro e História Editorial. Casa Rui Barbosa, Rio de Janeiro, 2004, p. 1. Disponível em: <http://www.livroehistoriaeditorial.pro.br/Mollier\%201.pdf>. Acesso em: 1 de outubro de 2015.

${ }^{6}$ Ibidem, p. 12

${ }^{7}$ Ibidem.
} 
apropriações e suas ressignificações em determinados contextos espaciais e temporais. ${ }^{8}$ Nesse aspecto, a esfera da circulação e de seus agentes - aqueles que a tornam possível - pode ser vista como o principal ponto de convergência entre a história do livro e a da imprensa. ${ }^{9}$

Essa convergência entre os dois campos de estudos - o do livro e o do jornal - pautou o desenvolvimento deste artigo, pois por meio da imprensa paulista buscou-se identificar os agentes da divulgação e da circulação de impressos (livros e jornais) na província de São Paulo, na década de $1870 . \mathrm{Na}$ realização desse trabalho, as fontes principais foram os anúncios de livreiros e de representantes de livrarias e periódicos nacionais e estrangeiros, bem como as seções que tematizaram o contexto da imprensa e dos leitores na província de São Paulo, veiculados em alguns jornais representativos da imprensa paulista na época, como A Província de São Paulo, a Gazeta de Campinas e o Diário de Campinas. ${ }^{10}$

A questão central que orienta esta análise é, portanto, a identificação do lugar ocupado por São Paulo no contexto de produção e circulação de impressos no Brasil, no decênio enfocado. Os estudos referentes a essa temática incidem, sobretudo, sobre a cidade do Rio de Janeiro. Angela de Castro Gomes, em estudo sobre a historiografia, salienta que o "Império (e a República) das Letras é setentrional e, naturalmente, tem o Rio de Janeiro como sua meca". ${ }^{11}$ Em parte, isso se explicaria pelo fato de o Rio de Janeiro ter sido o epicentro político-cultural do Brasil no século XIX. A instalação da Corte portuguesa, em 1808, por exemplo, impulsionou a criação e o desenvolvimento de tipografias, jornais, livrarias, teatros e outros espaços de sociabilidades que foram cruciais para o surgimento das condições objetivas de produção e consumo do livro, bem como de instâncias de consagração de autores no Brasil oitocentista. ${ }^{12}$

\footnotetext{
${ }^{8}$ A esse respeito, consultar: CHARTIER, Roger. Formas e sentidos. Cultura escrita: entre distinção e apropriação. Campinas (SP): Mercado de Letras/ABL, 2003.

${ }^{9}$ Exemplo disso é o projeto A circulação transatlântica dos impressos: a globalização da cultura no século XIX- que tem como um dos coordenadores Jean-Yves Mollier, defensor da não separação dos dois campos de estudo. O mencionado projeto envolve pesquisadores dos livros e da imprensa (jornais e revistas) preocupados em desvendar os caminhos desses impressos e as trocas culturais entre espaços diferentes por eles possibilitadas. ABREU, Márcia; MOLLIER, Jean-Yves. ABREU, Márcia; MOLLIER, Jean-Yves. A circulação transatlântica dos impressos: a globalização da cultura no século XIX. Disponível em: http://www.circulacaodosimpressos. iel.unicamp.br/. Acesso em: 8 de setembro de 2015.

${ }^{10}$ A pesquisa dos três periódicos foi realizada no Arquivo Edgar Leuenroth da Universidade Estadual de Campinas (Unicamp), onde se encontram microfilmados.

${ }^{11}$ GOMES, Angela de Castro. História e historiadores: a política cultural do Estado Novo. Rio de Janeiro: Fundação Getúlio Vargas, 1996, p. 44.

${ }^{12}$ Sobre a importância da transferência da família real na dinâmica sociopolítica e cultural da cidade do
} 
No caso de São Paulo, conforme ressalta Marisa M. Deaecto:

Já é um truísmo afirmar que São Paulo, ainda nos anos 1850-1860, era uma cidade modesta, e apresentava infraestrutura urbana elementar, modo de vida simples, sem luxo e pacata. o que se confirma nos relatos de viajantes que passaram amiúde a visitar o burgo a partir do segundo decênio do século, ou nas memórias deixadas por antigos moradores e pelos estudantes da Faculdade de Direito - que se tornaram, aos nossos olhos, verdadeiras crônicas de época. ${ }^{13}$

Essa visão de São Paulo como uma cidade pacata e de reduzido desenvolvimento urbano na primeira metade do século XIX pode explicar, em parte, mas não integralmente, o predomínio de um relativo silêncio na historiografia acerca das práticas culturais, da produção literária e da circulação de livros e ideias na província de São Paulo. Deaecto assevera que "é raro o caminho trilhado por aqueles que investigam [...] as práticas culturais que animavam os paulistas, do papel de sua imprensa periódica num primeiro momento e, posteriormente, dos livros, estes fomentadores de ideais". ${ }^{14}$

$* *$

Por que enfocar a circulação de livros e ideias na Província de São Paulo com base nos periódicos acima citados? Antes de tudo, porque se localizavam em núcleos urbanos importantes do âmbito provincial na segunda metade do século XIX - São Paulo e Campinas. Em outras palavras: porque se situavam em localidades expressivas da expansão cafeeira conjugada à malha ferroviária da Companhia Paulista, que incluía, em seu roteiro, um porto cosmopolita, na cidade de Santos; a capital da província, ponto de entroncamento de ferrovias (como a São Paulo Railway e a Ituana); Campinas, a capital agrícola; Itu, sede da Convenção Republicana; e a jovem Rio Claro. ${ }^{15}$ Ao lado da expansão econômica, a ferrovia, segundo Ana Luiza Martins, ajudava a transportar os "símbolos" da civilização:

Neste roteiro [o da Companhia Paulista] proliferavam teatros, escolas particulares cunhadas na proposta científica ao gosto do ideário da época, escolas noturnas para as camadas desfavorecidas, instituições culturais

Rio de Janeiro, ver: MALERBA, Jurandir. A corte no exílio: civilização e poder às vésperas da independência (1808-1821). São Paulo: Companhia das Letras, 2000. E a respeito das condições objetivas e/ou estruturais na criação dos mecanismos de produção artístico-literária, consultar: BOURDIEU, Pierre. As regras da arte: gênese e estrutura do campo literário. 2. ed. São Paulo: Companhia das Letras, 2010.

${ }^{13}$ DEAECTO, Marisa Midori. 0 império dos livros: instituições e práticas de leituras na São Paulo oitocentista. São Paulo: Edusp/Fapesp, 2011, p. 29.

${ }^{14}$ Ibidem, p. 29.

${ }^{15} \mathrm{Cf}$. DEBES, Célio. A Caminho do Oeste: subsídios para a história da Companhia Paulista de Estradas de Ferro e das Ferrovias de São Paulo (1832-1869). São Paulo: Edição comemorativa da Companhia Paulista, 1968. 
diversas, imprensa próspera, lojas maçônicas fortes e em todas elas gabinetes de leitura. ${ }^{16}$

Em tal cenário de florescimento econômico e cultural, as ferrovias influenciaram também a distribuição dos jornais, tornando-a diária a partir de 1873 (entre Santos, São Paulo, Jundiaí, Campinas e Itu, por exemplo). Nas localidades aonde os trilhos não tinham chegado, essa distribuição ainda era feita a cavalo. ${ }^{17}$

Tendo em vista que o propósito deste texto reside no exame da circulação de livros nos e pelos jornais, aventou-se a hipótese de que os periódicos selecionados não restringiam seu alcance aos leitores das cidades de São Paulo e Campinas, mas estendiam-no a um público mais amplo. Tal premissa, mesmo que indiretamente, tem-se confirmado na pesquisa, por meio dos indícios que os próprios jornais oferecem, seja em seus cabeçalhos (o preço da assinatura na localidade e fora dela), seja por meio dos próprios "reclames", como o da Livraria Internacional, publicado, em 24 de novembro de 1876, no Diário de Campinas, que informa: "Remmetem-se livros pelo correio ou estradas de ferro". ${ }^{18}$ Outras vezes, os jornais deixam ainda mais claros os lugares nos quais havia serviço de envio de livros e outros artigos, como figura na parte Avisos d'A Província de São Paulo, com a chamada Campinas-Encommmendas de Livros, em que a livraria campineira informa ao público:

Safisfazem-se prontamente quaisquer encomendas de livros das cidades seguintes: Mogy-Mirim, Limeira, Amparo, Rio Claro, Bethlem do Descalvado, Jundiay - QUADRO PARA SALAS, as últimas publicações, na LIVRARIA INTERNACIONAL. ${ }^{19}$

Essas cidades - Campinas e São Paulo - cumpriam, assim, o papel de centros irradiadores das discussões político-culturais para as outras paragens

\footnotetext{
${ }^{16}$ MARTINS, Ana Luiza. Gabinetes de Leitura da Província de São Paulo: a pluralidade de um espaço esquecido (1847-1890). Dissertação (Mestrado), Universidade de São Paulo, 1990, p. 160.

${ }^{17}$ SODRÉ, Nelson Werneck. História da imprensa no Brasil. Rio de Janeiro: Civilização Brasileira, 1966, p. 240. Acrescentem-se a isso as informações presentes no clássico trabalho de Laurence Hallewell acerca das condições objetivas dos impressos no Brasil: "A pequena cidade [São Paulo] já estava sendo observada pela atividade empresarial do paulistano. Já em 1867, um grupo de fazendeiros e de negociantes, reunido por Joaquim Saldanha Marinho, planejava a construção de uma estrada de ferro sem recorrer a qualquer capital estrangeiro: um projeto inédito. Em 1873, fora realizada a enorme façanha de ligar por trem Santos e São Paulo e, em 1875, uma estrada de ferro virtualmente completa ligava a cidade ao Rio de Janeiro". HALLEWELL, Laurence. O Livro no Brasil: sua história. 3. ed. São Paulo: Edusp, 2012, p. 340.

${ }^{18}$ Diário de Campinas, 24 dez. 1876, n. 660, p. 3. Optou-se por manter a ortografia, a sintaxe e a pontuação originais das fontes pesquisadas.

${ }^{19}$ A Província de São Paulo, 22 out. 1876, n. 521, p. 4 (destaque do original). O referido anúncio foi publicado em várias outras edições desse ano.
} 
da Província. E os jornais constituíam não apenas os principais veículos de disseminação das ideias por meio dos comentários de livros (fossem estes nacionais ou estrangeiros); eram também difusores do comércio das obras escritas, mediante os anúncios de livreiros estampados em suas páginas.

Ainda que, para a elaboração deste artigo, tenhamo-nos interessado especificamente pelos anúncios de livros e de impressos em termos gerais (periódicos e revistas), optou-se por vê-los no conjunto da formatação do jornal. Notamos, por exemplo, que havia um padrão, embora isso não constituísse regra, para os espaços relacionados à divulgação das Bellas Letras. Os textos de "prosa-de-ficção" eram publicados no rodapé - lugar que já se havia tornado tradicional na publicação dos folhetins -, quase sempre seguindo esta ordem: autores estrangeiros na primeira página e nacionais na segunda. O corpo dos jornais continha uma coluna fixa, designada Artes e Letras, nos jornais de Campinas, e outra, denominada Lettras e Artes, n'A Província de São Paulo, em que apareciam resenhas, comentários e discussões literárias. Embora não fosse, particularmente, relativa a temas literários, havia também a seção Bibliografia, na qual se apresentavam obras e autores - que, aliás, foi mais constante n'A Província de São Paulo. Havia também a coluna Variedades. Entre outros formatos literários, publicavam-se trechos de folhetim. Na parte Noticiário e Avisos, era comum divulgar publicações e agradecer por livros, jornais e revistas recebidos. Sem seção específica, poemas foram publicados na primeira e na segunda página dos jornais. Nas últimas (terceira e quarta), entre anúncios em geral, figuravam os reclames de livreiros de Campinas, São Paulo e Rio de Janeiro - além de muita publicidade de periódicos estrangeiros.

Foi por meio dessa visão mais ampla acerca da estruturação dos jornais que se tornou possível verificar o lugar central que a discussão sobre a circulação de impressos e seus leitores em potencial ocupava nos periódicos paulistas - como se verá adiante. Tal suporte de veiculação de ideias era visto pelos letrados como o lugar por excelência de instrução e ilustração, ou seja, o espaço em que se cumpriam os ideais civilizatórios.

Enfim, os periódicos foram eleitos como uma espécie de "museu natural" e de "manual histórico em miniatura", para usar os termos de Flora Süssekind, ao referir-se à imprensa brasileira das primeiras décadas do século XIX:

E, museus de tudo, as folhas recreativas e as "Miscelâneas", seções de "Variedades", "Folhetins", "Apêndices" e "Fatos Diversos" dos periódicos das primeiras décadas do século XIX talvez tenham sido, a seu modo, uma espécie de versão local da Encylopédie. Assim como 
tentativas conscientes de suprimir falhas na formação e na instrução de seus leitores potenciais. ${ }^{20}$

Não obstante os jornais selecionados para o presente artigo situem-se numa periodização distinta daquela dos periódicos tratados pela autora, considerá-los como uma versão local da Encyclopédie tem sido proveitoso, como recurso instrumental, para o desenvolvimento deste trabalho investigativo. Afinal, apesar da inserção cultural de tais periódicos não ter sido dissociada da política republicana - partidária ou não -, os jornais pretendiam-se veículos de instrução e civilização. Ademais, boa parcela dos homens ligados à Província de São Paulo, à Gazeta de Campinas e ao Diário de Campinas era fruto social da expansão econômica da Província. Portanto, a escolha desses periódicos explica-se não somente pelo fato de haverem sido publicados em localidades provinciais representativas da expansão cultural e econômica local - como acima explicitado -, mas também por terem sido atuantes no processo de sua modernização, em parte influindo na constituição de um mercado livreiro em São Paulo, bem como de uma determinada cultura de leitura, a qual, por sua vez, interferiu na formação de uma cultura política.

\section{O jornal a "preço de um máo charuto"}

No Brasil do Oitocentos, a imprensa era considerada um dos índices indicadores da civilização e do progresso de um país. Desde as fases iniciais de nossa imprensa, é possível notar a tendência em inventariá-los. Nesse sentido, Tania Bessone e Lúcia Bastos Neves nos dão notícia de que:

[A revista] O Beija Flor [annaes brasileiros de sciencia, política e literatura], em seu quarto número [publicado em 1830], trazia uma interessante e sugestiva informação sobre a imprensa no Brasil. Afirmava que em 1827 registravam-se apenas 12 ou 13 periódicos e, naquele momento, conforme "conta retirada da Aurora[Fluminense]", totalizavam 54 para todo o Império; destes, 16 pertenciam à Corte, sendo que em 1827, havia apenas 8. Desse modo, "se os progressos da Imprensa fossem os degraus certos de um termômetro para o adiantamento da civilização, podíamos nos felicitar de nosso avançamento, pois que de quatro anos para cá o número das publicações periódicas tem quadruplicado no Brasil. ${ }^{21}$

${ }^{20}$ Süssekind, Flora. O Brasil não é longe daqui: o narrador, a viagem. São Paulo: Companhia das Letras, 1990, p. 78-79

${ }^{21}$ BESSONE, Tania; NEVES, Lúcia Bastos Pereira das. Impressores, livreiros, livros e conceitos: circuito de circulação das ideias entre Brasil, Portugal e França, ao longo do Oitocentos. Disponível em: http://redeshistoria. pro.br/c.php?c=projetos-em-andamento; Acesso em: 20 jul. 2015, p. 11. 
Passadas mais de três décadas dessa estatística publicada pel'o Beija-Flor, em um contexto de apresentação da imagem do País na Exposição Universal de 1876, ocorrida na Filadélfia (EUA), o Império realizou um relatório com o objetivo de apresentar informações sobre a imprensa no Brasil. Os dados contidos nesse relatório foram divulgados pela imprensa brasileira. No que toca à imprensa paulista, foi publicada, na seção Noticiário d'A Província de São Paulo, uma relação com o número de órgãos de imprensa no Brasil, conforme os dados mencionados no relatório, reproduzidos a seguir:

Jornalismo no Império - Segundo o relatório destinado á exposição universal de 1876, em Philadelphia, publica-se no Brazil o seguinte numero de diarios, semanários, revistas scientificas, folhas caricatas, etc., referidas conforme as respectivas províncias e município neutro.

\begin{tabular}{|c|c|}
\hline Côrte & 44 \\
\hline S. Paulo & 43 \\
\hline Rio de Janeiro & 25 \\
\hline Rio Grande do Sul & 25 \\
\hline Pernambuco & 23 \\
\hline Bahia & 21 \\
\hline Pará & 17 \\
\hline Minas Geraes & 16 \\
\hline Ceará & 9 \\
\hline Espírito Santo & 9 \\
\hline Alagoas & 9 \\
\hline Rio Grande do Norte & 7 \\
\hline Piauy & 7 \\
\hline Amazonas & 6 \\
\hline Parayba & 6 \\
\hline Santa Catharina & 5 \\
\hline Sergipe & 4 \\
\hline Goyas & 2 \\
\hline Matto-Grosso & 2 \\
\hline & \\
\hline & 216 \\
\hline
\end{tabular}

A soma geral ascende á $293 .^{22}$

${ }^{22}$ A Província de São Paulo, 9 jan. 1876, n. 292, p. 3. 
Dos 293 impressos, a Província do Rio de Janeiro (junto aos periódicos da Corte) totalizou 69 periódicos. Em seguida, vinha São Paulo, com 43 publicações. Esses dados foram motivo de regozijo entre os paulistas e parecem ter mobilizado na imprensa uma discussão acerca do índice de civilização que essas informações representavam. Ao menos, os paulistas apropriaram-se dos mencionados subsídios, na ocasião, para referendar uma autorrepresentação que vinha ao encontro de um momento de prosperidade econômica e de modernização nos hábitos e costumes da São Paulo provincial.

No editorial de A Província de São Paulo, no artigo Jornais e leitores - publicado, com duas colunas, na primeira página -, é possível ter uma ideia do que tais dados sobre a imprensa paulista suscitaram na ocasião:

Uma estatística, que corre na imprensa, dá a S. Paulo como uma das províncias que possuem maior numero de publicações periódicas. Mais de uma vez esses dados encheram estirados periódicos em louvor de nossa virilidade provinciana. ${ }^{23}$

Conquanto o autor não coloque em dúvida o lugar de primazia da imprensa paulista, quando comparada com a de outras províncias do Brasil (como a de Pernambuco, por exemplo), ele prossegue o artigo de maneira bastante instigante, afirmando que as estatísticas haviam provocado pronunciamentos eufóricos por parte da imprensa do País, em especial da Província de São Paulo. No entanto, indaga se os elogios eram feitos "Com razão? Com exageração?". Ao que ele mesmo responde: "Há ahi mais rethorica que realidade". Isso porque, segundo o articulista, "faltam leitores". Em sua opinião, esses ledores não dispensariam os "figurinos parisienses", a "cerveja dos alemães”, as "estradas de ferro", os "engenheiros" ingleses... Sua conclusão é a de que, distintamente dos "grandes centros civilizados, quer da Europa, quer da América do Norte, e mesmo do Rio da Prata; dispensa-se, no Brasil, aquilo que é essencial - a leitura, as bibliotecas, o livro e o jornal". ${ }^{24}$

Importa observar que a prática de leitura não se limitava àqueles que sabiam ler, mas também incluía os analfabetos, os quais ouviam os que outros liam em voz alta (ou seja, "liam" por intermédio da oitiva). Mesmo levando em conta essa prática, é importante sabermos o número de alfabetizados na Província de São Paulo, no período. A Gazeta de Campinas, em 1877, reproduz os dados sobre o analfabetismo na região provincial de São Paulo, com base nas informações estatísticas do inspetor de instrução pública da Província.

\footnotetext{
${ }^{23}$ A Província de São Paulo, 23 jan. 1876, n. 304, p. 1. ${ }^{24}$ Idem.
} 
Segundo esses dados, os analfabetos eram maioria, tanto entre os membros da população livre quanto entre os escravos. Numa totalidade populacional de " 873.354 almas, são analfabetos 253.327 homens e 248.348 mulheres livres e 87.059 homens e 68.549 mulheres escravas, perfazendo uma soma de 696.183 analphabetos". ${ }^{25}$

Consideradas essas informações sobre o analfabetismo na Província de São Paulo, é possível dizer que o articulista tinha razão: "Faltam leitores". Entretanto, também é preciso levar em conta o lugar social ocupado pelo autor do texto em questão. $\mathrm{O}$ artigo faz parte do editorial. Na maioria das vezes, nessa seção eram publicados escritos saídos da pena de seus redatores. N'A Província de São Paulo, figuraram como redatores Rangel Pestana e Américo de Campos, que também estavam à frente do jornal, do qual eram seus dois maiores acionistas. $O$ citado escrito foi publicado quando o jornal tinha somente um ano de existência (1876) e passava por uma fase financeira difícil. ${ }^{26}$ Não se pode desconsiderar esse contexto, pois provavelmente tal conjuntura também influiu no diagnóstico, acima referido, sobre a leitura no Brasil.

Talvez seja por essa razão que o redator insistiu em afirmar, no artigo, e por diversas vezes, que as "mais modestas fortunas" não vacilavam em gastar seu dinheiro com "despesas de ocasião":

[...] meia dúzia de garrafas de cervejas ou uma ceia no Restaurant, acolá uma boneca que fala ao afilhado, outro dia um passeio de carro nos arrabaldes, mais adiante uma caixa de charuto, depois, aquela futilidade galante de uma modista, adiante outra preciosidade ainda mais fútil. ${ }^{27}$

No que diz respeito ao jornal, a "cousa é outra”, segundo o articulista:

Sómente os mais ousados atrevem-se á prodigalidade de assignar uma folha, cuja despeza entretanto é dous ou três vinténs por dia; o preço de um máo charuto; a metade ou o terço do valor de um havano; a sexta ou sétima parte do que custa um sorvete; o custo de um café no botequim!. ${ }^{28}$

\footnotetext{
${ }^{25}$ Gazeta de Campinas, "Instrucção publica”, 5 maio 1877, n. 1026, p. 2.

${ }^{26} \mathrm{Cf}$. SCHWARCZ, Lilia Moritz. Retrato em branco e negro: jornais, escravos e cidadãos em São Paulo no final do século XIX. São Paulo: Companhia das letras, 1987, p. 88.

${ }^{27}$ A Província de São Paulo, 23 jan. 1876, n. 304, p. 1.

${ }^{28}$ Ibidem, (grifos nossos). É importante, com respeito ao periódico mencionado, registrar o valor do jornal avulso e das assinaturas semestral e anual para a localidade e fora dela. Seguem os dados, que são relativos ao ano em que foi publicado o editorial do qual estamos tratando. Era habitual aparecerem no alto da primeira página os citados valores: “Assignaturas para a capital: anno $14 \$ 000$, semestral $7 \$ 000$. Assignaturas para fora: anno - $18 \$ 000$, semestre $9 \$ 000$. As assignatura pòde começar em qualquer dia e mez mas terminará em junho e dezembro. Todos os pagamentos adiantados. Número avulso - 200 rs. Typografia e escritório - Rua de Palácio N. 14".
} 
Esses detalhes acerca dos produtos cujo preço equivaleria ou era muito maior que o da folha diária parecem denotar uma preocupação legítima de alguém que estava à frente de um jornal. Na mesma época do artigo em foco, A Província de São Paulo - como forma de aumentar a venda de exemplares inaugurou em São Paulo uma nova prática: o da venda avulsa do jornal nas ruas (desde 23 de janeiro de 1876). Até essa data, a venda avulsa só era feita nas redações e oficinas dos periódicos paulistas. A ideia veio do francês Bernard Gregoire - funcionário da oficina -, que já havia tido essa experiência, quando trabalhava no Le Petit Journal, de Paris, o qual tinha como proprietário Möise Polydore Millaud. Este, seguindo os passos de Émile de Girardin, revolucionou a imprensa francesa, tornando-a um meio de comunicação de massa. ${ }^{29}$ Gregoire passou a usar as páginas de anúncio d'A Província de São Paulo para listar quais eram os jornais por ele vendidos e para divulgar a nova prática. Vejamos um anúncio datado de 30 de janeiro de 1876 e a cuja diagramação se obedece:
Vendedor de jornaes
MR. BERNARD GREGOIRE, condecorado com a Cruz de Bronze e a Medalha de Honra, ex-vendedor do "Petit Journal" de Pariz e da "Gazeta de Noticias" do Rio de Janeiro, tem a honra de prevenir ao respeitável publico o seguinte: Todos os dias vende o jornal - A PROVINCIA DE SÃO PAULO, nas ruas e na estação da linha férrea.
Aos domingos também venderá o COARACY.
S. Paulo, 29 de janeiro de $1876 .{ }^{30}$

O artigo do qual se vem tratando - Jornaes e Leitores - é muito valioso para o presente texto. Com efeito, além de propiciar os subsídios já expostos, também permite pensar que, mesmo depreciando o hábito de consumo das últimas novidades europeias em detrimento da aquisição de jornais e de livros, seu autor acaba por dar os indícios das transformações urbanas e dos hábitos vigentes na década de 1870. Uma série de produtos é anunciada nas páginas três e quatro dos jornais paulistas selecionados, até mesmo os charutos e a moda francesa (aos quais aludiu o articulista). E ainda eram apregoados os chocolates "Marquis"; lojas especializadas nas modas feminina, masculina e

\footnotetext{
${ }^{29}$ Conforme Marlyse Meyer, Le Petit Journal é o "protótipo e sinônimo de toda a chamada petite presse, sem pretensões políticas ou literárias, visando as novas camadas sociais que aderiram à leitura e ao prazer de um novo romanesco multiplicado pelas folhas baratas e rapidamente divulgadas. Porque Millaud não só inventa um novo gênero jornalístico como também um sistema de distribuição nacional rápido e eficiente, [inaugurando] a fórmula de venda avulsa". MEYER, Marlyse. O Folhetim: uma história. São Paulo: Companhia das Letras, 1996, p. 97.
}

${ }^{30}$ A Província de São Paulo, 30 jan. 1876, n. 309, p. 4. 
infantil; produtos para facilitar a vida doméstica; máquinas para aumentar a produtividade...

Em meio aos anúncios de uma diversidade de mercadorias (e até da compra e venda de escravos), divulgavam-se muitos e muitos livros, além de jornais nacionais e estrangeiros, nas páginas dos periódicos pesquisados. Se anunciavam toda essa variedade de itens, a nosso ver, é porque existiam consumidores e leitores. 0 próprio editorial do qual falamos, relata, embora com um certo desdém:

[...] a mãe de família percorre uma vez ou outra os annuncios, o obituário; meia hora depois o jornal é transformado em chapéu armado a coroar a cabecinha do buliçoso anginho do lar, que é afinal de contas [...] quem melhor aprecia o desdenhado quadrado de papel. ${ }^{31}$

Em contraposição a esse parecer negativo do editorial d'A Província de São Paulo, encontramos a reprodução, no ano seguinte (1877), de um artigo (publicado originalmente no jornal Instrução Popular, do Rio de Janeiro) na Gazeta de Campinas. Não foi por acaso que sua publicação se deu no jornal campineiro, pois particularizava a Província de São Paulo no que tange ao hábito da leitura. $\mathrm{O}$ artigo em questão tem um teor explicitamente político; exalta os paulistas no que se refere às iniciativas individuais no âmbito dos melhoramentos no setor de transportes, com a construção de estradas de ferro; também elogia a esfera educacional, salientando a criação de várias escolas, com ênfase para o colégio Culto à Ciência, de Campinas - iniciativa, diga-se de passagem, dos republicanos -, como instituição que preparava os jovens para "as lutas da civilização e do progresso"... Indagava o articulista: "Qual a rasão deste phenomeno? [...] Porque a província de S. Paulo tanto se distingue entre outras?". Tal particularidade, segundo o artigo, devia-se a este fato: "É em S. Paulo onde mais se lê". ${ }^{32}$

Com muitos ou poucos leitores - de acordo com as representações que se vêm examinando -, a verdade é que o número de "reclames" de livrarias e de seus agentes foi abundante nos anos 1870. Nas últimas páginas, três e quatro, entre anúncios em geral, figuravam os anúncios de livreiros de Campinas, São Paulo e Rio de Janeiro - e também muita publicidade de periódicos estrangeiros. Anunciavam-se, igualmente, as publicações de revistas e almanaques; por exemplo, os almanaques literários de São Paulo e de Campinas, a revista República das Letras, de São Paulo, etc. - empreendimentos levados a cabo

\footnotetext{
${ }^{31}$ A Província de São Paulo, 23 jan. 1876, n. 304, p. 1.

${ }^{32}$ Gazeta de Campinas, 19 jan. 1877, n. 949, p. 1.
} 
pelos mesmos homens ligados aos jornais em estudo. Essas práticas indicam que havia uma ampla e diversificada difusão de impressos e apontam, indiretamente, para a esfera do universo de consumidores e leitores na Província de São Paulo.

De acordo com Laurence Hallewell, no decorrer das décadas de 1860 e 1870 é que se deu o início da emergência do comércio livreiro na capital paulista, impulsionado pelos estudantes da Academia de Direito e por uma série de transformações materiais associadas à expansão da cafeicultura. A atividade cafeeira aumentou a riqueza circulante e imprimiu hábitos de uma vida tipicamente urbana à cidade de São Paulo. Portanto, para o autor, foi na segunda metade do século XIX que se assistiu, em São Paulo, à emergência do comércio das obras escritas, com destaque para o papel do francês A. L. Garraux. Este, que se tornaria o livreiro mais importante de São Paulo no último quadriênio do Oitocentos, iniciou sua trajetória na condição de empregado de uma filial da famosa livraria de Baptiste Louis Garnier (cuja inauguração aconteceu em 1844, no Rio de Janeiro), instalada na cidade de São Paulo, em 1860. Esse fato, por si, como sublinha Hallewell, denota a existência de uma significativa demanda por livros em São Paulo:

Em 1860, o livreiro Baptiste Louis Garnier, do Rio de Janeiro, abriu uma filial
em São Paulo, fato por si só indicador de que o mercado de livros ali já era
de bom tamanho, e confiou a Anatole Louis Garraux (1833-1904), que vinha
trabalhando para ele desde que chegara da França com dezessete anos. Em 1863
Garraux já se tornara independente de Garnier e abrira a Livraria Acadêmica em
sociedade com Guelfe de Lailhac e Raphael Suarez, embora a firma continuasse
a ser chamada por todos de Casa Garraux, até muito tempo depois de Garraux
a ter vendido e regressado para Paris. ${ }^{33}$

Além de A. L. Garraux, quais teriam sido os livreiros que publicaram anúncios nos jornais de São Paulo e Campinas? Para responder à pergunta, buscou-se identificar os itinerários dos mediadores no universo dos impressos (as redes de pessoas envolvidas nesse universo) - livreiros, editores, vendedores ambulantes e agentes de livrarias e de periódicos - tomados aqui como "transmissores culturais ativos", na expressão de Diana CooperRichet, por sua função e por seu desempenho na vida cultural, política e editorial do período. ${ }^{34}$

\footnotetext{
${ }^{33}$ HALLEWELL, op. cit, p. 226-227.

${ }^{34}$ COOPER-RICHET, Diana; MOLLIER, Jean-Yves; SILEM, Ahmed (Orgs.). Passeurs culturales dans le monde des médias et de l'édition en Europe: XIX e XX Siècle. Villeurbanne: E.N.S.S.I.B, 2005.
} 


\section{Alguns mediadores culturais: livreiros e agentes de impressos}

Por meio dos anúncios publicados n'A Província de São Paulo, foi possível constatar que, embora a Livraria Brasileira-Allemã, de Ricardo Mattes, ocupasse um espaço relevante, tanto no que tange à página ocupada por seus anúncios quanto no que se refere à frequência com que anunciava, a preeminência era de A. L. Garraux no mercado livreiro de São Paulo. A Livraria Academica, de Garraux, chegava a ocupar quase uma página inteira da edição dominical (em vários números, no período de 1875 a 1876). Tendo por base o referido anúncio, pode-se verificar que a Casa Garraux buscava construir sua singularidade em relação aos livreiros da Corte, recorrendo, para tanto, à estratégia da rápida entrega dos livros e periódicos estrangeiros, os quais, "sendo recebidos diretamente da Europa pelo correio são entregues antes das assignaturas feitas por intermédio de qualquer casa do Rio de Janeiro, é impossível haver maior celeridade" ${ }^{35} \mathrm{O}$ anúncio em questão não somente mostra que a ligação de Garraux se dava de maneira direta com a Europa, isto é, sem a intermediação feita por livreiros da Corte, mas também busca demarcar a sincronia do Brasil com o resto do mundo "civilizado". Sobre esse aspecto, encontramos um dado, num anúncio da Livraria Internacional, de Campinas, que mostra a ligação direta desse estabelecimento com os livreiros de Portugal: "Tendo chegado de Santos uma avultada remessa de livros feita pela Livraria Moré, do Porto, resolvemos liquidar diversas facturas, fazendo considerável abatimento dos preços". ${ }^{36}$

Ademais, por meio da Gazeta de Campinas e do Diário de Campinas, descobrimos dois agentes de A. L. Garraux na cidade, na década de 1870: Alexandre Pirret e Romão Vidal. ${ }^{37}$ Acrescente-se aos nomes desses dois o do escocês John H. Bryan - representante de diversos periódicos estrangeiros e nacionais, com destaque para o jornal o Novo Mundo, impresso, em Nova Iorque, por José Carlos Rodrigues, ${ }^{38}$ e para a Gazeta de Notícias, publicada, no Rio de Janeiro, por

\footnotetext{
${ }^{35}$ A Província de São Paulo, 6 jan. 1876, n. 291, p. 4.

${ }^{36}$ Diário de Campinas, 28 dez. 1877, n. 660, p. 3.

${ }^{37}$ Esses "novos profissionais" - representantes de livreiros e de editoras - originaram-se do desenvolvimento do contexto editorial no final do século XIX, o qual se beneficiou do aperfeiçoamento das técnicas de impressão. A esse respeito, Márcia Abreu e Jean-Yves Mollier afirmam: "Durante as últimas décadas do século XIX, outras inovações tecnológicas aceleraram o ritmo da produção de impressos: a impressão rotativa, a partir de 1870; a linotipia nos anos 1880; e utilização da litografia e da fotografia no final do século. A introdução da eletricidade, nesta fase, propiciou um avanço ainda maior, permitindo um incremento notável na produção de impressos. Tudo isso favoreceu, evidentemente, os vários ramos do sistema editorial, tornando necessários novos profissionais (como os agentes literários, por exemplo) e novas associações (como as dos representantes de editores e livreiros)". ABREU; MOLLIER, op. cit, p. 3.

${ }^{38} \mathrm{Em} 1867$, J. C. Rodrigues foge para Nova Iorque, a fim de escapar da Justiça. Na capital dos Estados Unidos, além de tornar-se correspondente do Jornal do Commercio, dirigiria um jornal brasileiro de sua propriedade,
} 
Ferreira de Araújo. Além de muitos dos textos publicados no jornal carioca serem reproduzidos na imprensa paulista, ocorre também a divulgação do empreendimento jornalístico por meio dos reclames de seu representante em Campinas. Vejamos:

\section{Gazeta de Notícias}

Desde que estiver organizado o serviço de comboyos expressos entre a Côrte e S. Paulo começará a venda avulsa e diária, nesta cidade, daquele jornal, o de maior tiragem e mais bem informado da corte, e notável pela imparcialidade do seu Diario das Câmaras, juízos verdadeiros sobre as questões mais palpitantes, e variedades de noticias.

Precisa-se de pessoas que se encarreguem da venda a cargo do agente.

Jonh H. Bryan

Rua do Caracol

Sala contigua a Livraria Internacional ${ }^{39}$

Afora esses representantes acima mencionados, nos anos 1870, três outras livrarias aparecem nas páginas dos anúncios: a já mencionada Livraria Internacional, de Gaspar da Silva, a qual mudaria de proprietário em 1878, passando a chamar-se Meynar \& Comp.; a Paraíso Terrestre, de Guilherme de Lima; e a Livraria Universal, de Henrique de Barcellos (1879-1881). Além desses estabelecimentos, outras firmas comerciais vendiam livros, mas não se identificavam como "livreiros": Roberto Alves \& Mendes; Irmão e Nogueira; Cerqueira Amaral; e França Camargo \& Irmão. A última "sociedade" - França Camargo \& Irmão - era a agente, em Campinas, da famosa livraria B. L. Garnier, do Rio de Janeiro, no período aqui em análise. Na parte superior de seus anúncios figurava esta inscrição: "Livraria B. L. Garnier - Agentes em Campinas - França Camargo \& Irmão”.

Observamos também que todo final de lista de livros que compunham os anúncios dos agentes da Garnier em Campinas trazia a nota de que os volumes seriam vendidos a "Preços do Rio a dinheiro - Largo do Rosário - França Camargo e Irmãos", ${ }^{40}$ como estratégia para atrair os consumidores. Entre 1877 e 1878, esses agentes da mencionada livraria Garnier em Campinas publicaram com frequência um mesmo anúncio em várias datas. 0 "reclame" em questão continha títulos de autores nacionais e estrangeiros. Quem encabeçava a

O Novo Mundo (1870-1879), e um periódico, A Revista Industrial. De volta ao Brasil após vinte anos - período em que o processo contra ele prescrevera -, passou ser proprietário do Jornal do Commercio. Sobre o jornalista, ver: HALLEWELL, op. cit, p. 161-162.

${ }^{39}$ Diário de Campinas, 05 jul. 1877, n. 522, p. 3 (grifo do original).

${ }^{40}$ Gazeta de Campinas, 17 mar. 1877, n. 987, p. 4 (grifo do original). 
lista dos brasileiros era José de Alencar, com 10 (dez) romances, ${ }^{41}$ seguido de Bernardo Guimarães, com livros de poesia e do gênero romanesco; ${ }^{42}$ Joaquim Manuel de Macedo, com 5 (cinco) romances; ${ }^{43}$ Fernandes Pinheiro, com obras de história literária e seu famoso compêndio História Sagrada. ${ }^{44}$ Entre os autores estrangeiros, figuram no anúncio as obras completas de Júlio Verne (23 volumes brochados a $48 \$ 000$ ), ao passo que Victor Hugo comparece com apenas um título, o romance Noventa e três (1 volume, a $3 \$ 000)$. Depois de discriminar esses autores, são feitas referências gerais sobre parte do repertório livresco que podia ser encontrado na livraria Garnier e encomendado por intermédio dos agentes em Campinas: "Manuais de missa, Horas mariannas, livros para a infância, arithmética, grammatica, leitura, história, desenho e uma grande colleção das obras mais notáveis nacionnaes e estrangeiras." ${ }^{45}$

Um aspecto digno de destaque é o fato de que, em razão da presença de representantes do livreiro Garnier em Campinas (embora um número pequeno de obras fosse por eles anunciado, quando comparado com o acervo de nosso maior livreiro), o leitor poderia encomendar qualquer título que fizesse parte da coleção da livraria do Rio de Janeiro. O título desejado sempre constava dos catálogos elaborados pela Garnier e distribuídos no País, com o intuito de fazer propaganda de seu negócio. Assim, é possível fazer as seguintes indagações sobre o anúncio mencionado: Por que, em um universo amplo como o dito acervo, selecionavam-se determinados autores e obras? Quem os escolhia? Eram os agentes ou o próprio Garnier? Curiosamente, este último havia sido o editor de José de Alencar, Bernardo Guimarães, Joaquim Manuel de Macedo e Fernandes Pinheiro. ${ }^{46}$ Com isso, pode-se levantar a hipótese de

\footnotetext{
${ }^{41}$ Os romances são os seguintes: O Guarany (2 volumes brochados, $6 \$$ ), O Sertanejo ( 2 volumes brochados, $4 \$$ ), Senhora (2 volumes brochados, $4 \$$ ), 0 Til (4 volumes brochados, $4 \$$ ); Cinco Minutos (1 volume encadernado, $3 \$$ ), 0 Ermitão ( 1 volume brochado, 2\$), O Garatuja (1 volume brochado, 2\$), Lucíola (1 volume brochado, $2 \$)$ e Ubirajara (1 volume brochado, $2 \$$ ).

${ }^{42}$ Poesias (1 vol. encadernado, 6 ), Maurício (2 vols. brochados, 4\$), A Escrava Isaura (1 vol. brochado, $2 \$$ ), 0 Garimpeiro (1 vol. brochado, $2 \$$ ), Histórias e tradicções (1 vol. brochado, $2 \$)$, Lendas (1 vol. brochado, $2 \$$ ) e 0 Indio Afonso (1 vol. brochado, $1 \$$ ).

${ }^{43}$ O Forasteiro (3 vols. brochados, $6 \$$ ), O Moço Louro (2 vols. brochados, $4 \$$ ), Rosa (2 vols. brochados, $4 \$$ ), Dois Amores (2 vols. brochados, $4 \$$ ) e A Moreninha (1 vol. brochado, $2 \$$ ).

${ }^{44}$ Litteratura (1 vol. $\left.7 \$\right)$, Litteratura (2 vols., 17\$), História Sagrada (1 vol. 3\$), História contemporanea (1 vol. 3\$), Historia pátria (1 vol. 2\$), Cathecismo (1 vol. 1\$) e Grammatica da infância (1 vol. 1\$).

${ }^{45}$ Gazeta de Campinas, 17 mar. 1877, n. 987, p. 4. A respeito da diversidade de manuais e sua popularização a partir da década de 1870, consultar: EL FAR, Alessandra. Páginas de sensação: literatura popular e pornográfica no Rio de Janeiro (1870-1924). São Paulo: Companhia das Letras, 2004.

${ }^{46} \mathrm{~A}$ esse respeito, ver: QUEIROZ, Juliana Maia de. "Em busca de romances: um passeio por um catálogo da livraria Garnier". In: ABREU, Márcia (Org.). Trajetórias do romance: circulação, leitura e escrita nos séculos XVIII e XIX. Campinas, SP: Mercado de Letras, 2008.
} 
que o editor-livreiro investia consideravelmente na publicidade das obras que editava. Na esteira dessa suposição, é plausível pensar que fosse o próprio Garnier quem selecionava os autores e obras a serem apregoados por seus promotores em Campinas.

Juntamente com os anúncios de livros divulgados pelos representantes de livrarias - como acima explicitado -, por meio dos jornais pesquisados, foi possível observar reclames relativos à prática da subscrição com o objetivo de publicar uma obra ou um jornal, a qual esteve presente desde o início de nossa imprensa, com a finalidade de informar os locais onde as listas de subscrição poderiam ser encontradas. Exemplifico o fato com um anúncio de M. Gomes de Almeida - impresso em 5 de janeiro de 1878, n'o Diário de Campinas. A nota publicitária em questão refere-se a um projeto de publicação de um jornal (que se denominaria A América - dupla edicção de uma folha na Europa), ${ }^{47}$ e continha o plano para as edições estrangeira e brasileira. Além dos temas que deveria conter em ambas as edições, o anúncio traz as condições para as assinaturas referentes à edição brasileira: o valor (30\$000 anuais adiantados), seguido da listagem dos lugares onde se poderia efetuá-las, ou seja, nas casas de pessoas ilustres residentes em Campinas: "Barão de Indayatuba, Floreano Ferreira de Camargo Andrade, Dr. Campos Salles, João Murthé, Dr. Luiz Silveira Alves Cruz, Coronel Joaquim Quirino dos Santos, Guilherme Villares e Francisco Glycerio". 48

Transcorridos quase quatro meses dessa publicação, saíram notícias acerca do referido projeto na sessão Factos Diversos do jornal, que traz a seguinte chamada, intitulada Sobre o sr. M. Gomes de Oliveira, o do jornal A America:

Acha-se de volta a esta cidade o sr. M. Gomes de Oliveira, que há tempos aqui veiu no intuito de angariar assignaturas para o jornal A America, publicação que deve ser impressa em Paris, e que é destinada a fazer conhecido o Brazil aos povos de além-mar. $\mathrm{O}$ sr. Gomes de Oliveira deixara algumas pessoas desta cidade encarregadas de colher assignaturas para essa folha e agora vem recolher as respectivas listas. ${ }^{49}$

Apesar de, nas edições subsequentes do Diario de Campinas, não mais ter sido encontrada qualquer notícia a respeito do Sr. M. Gomes de Almeida e do jornal A America, a iniciativa da subscrição de um jornal que seria editado em Paris - para o público europeu inteirar-se dos assuntos referentes ao Brasil e

\footnotetext{
${ }^{47}$ Diário de Campinas, 05 jan. 1878, n. 672, p. 4.

${ }^{48}$ Ibidem.

${ }^{49}$ Diário de Campinas, 25 abr. 1878, n. 758, p. 2 (grifos nossos).
} 
para o público brasileiro atualizar-se quanto à Europa - por si já mostra um dos caminhos trilhados pela imprensa brasileira: o de se estabelecer também no Exterior. Nesse aspecto, independentemente de o jornal haver ou não se concretizado,,$^{50} \mathrm{o}$ anúncio interessou-nos por conter uma das práticas que caracterizaram a trajetória dos impressos no Brasil oitocentista - e que muito diz sobre o movimento da circulação transatlântica de impressos e pessoas, bem como a respeito das conexões estabelecidas entre o Brasil e o além-mar. ${ }^{51}$ Quase uma década depois do reclame em questão, tivemos o empreendimento bem-sucedido de Mariano Pina (1860-1889), editado em Paris e denominado A Ilustração - revista de Portugal e Brasil, que circulou em Portugal e em terras nacionais, entre 1884 e $1892 . .^{52}$

$\mathrm{O}$ anúncio sobre o qual se está discorrendo suscita diversas indagações: tirante o Sr. M. Gomes de Almeida, quem seriam as outras pessoas envolvidas no projeto de criação de um jornal brasileiro, mas que seria editado em Paris? Gomes de Almeida seria o principal empreendedor ou representava a iniciativa de outrem? A direção do periódico estaria sediada em São Paulo ou no Rio de Janeiro? Infelizmente não temos subsídios para responder a tais questões. De qualquer maneira, o reclame evidencia uma das práticas vigentes na e para a circulação de impressos no universo da imprensa nacional.

Fundamentando-nos no até agora exposto, nota-se que o itinerário do comércio de impressos na Província de São Paulo, na década de 1870, ocorria principalmente através da ligação direta com a Europa, mais especificamente Paris (por intermédio do livreiro A. L. Garraux), e a cidade do Porto (Portugal), caso das obras adquiridas por Gaspar da Silva, da Livraria Internacional, de Campinas. Assim como Garnier, o livreiro da capital paulista, A. L. Garraux, também tinha seus agentes em Campinas, como já explicitamos. Portanto, as conexões do comércio de impressos nas cidades de São Paulo e Campinas

\footnotetext{
${ }^{50}$ Nas pesquisas feitas tanto na Hemeroteca da Biblioteca Nacional do Rio de Janeiro quanto no site da Gallica da Biblioteca Nacional da França, não encontramos o jornal com essa denominação. Isso nos leva a dizer que, provavelmente, o projeto não foi levado a cabo.

${ }^{51}$ Entre várias experiências de impressos, as que estão em destaque mostram que os caminhos dos impressos e a circulação das ideias foram múltiplos, não unidirecionais - da Europa para o Brasil. Também foram feitos no sentido inverso - do Brasil para a Europa. A esse respeito o projeto coordenado por Márcia Abreu e Jean-Yves Mollier - já mencionado - que reúne pesquisadores brasileiros e estrangeiros, assevera que: "Não se deve pensar que o trânsito da produção editorial inglesa, francesa, portuguesa e brasileira oitocentista seguia um fluxo unidirecional, da Inglaterra e França para Portugal e de lá para o Brasil. Pelo contrário, os impressos, as pessoas e as ideias circulavam entre estes diferentes lugares". ABREU; MOLLIER, op. cit, p. 11. ${ }^{52}$ LUCA, Tania de. “A Ilustração (1884-1892): algumas questões teórico-metodológicas”. In: ABREU, Márcia; DEAECTO, Marisa M. A circulação transatlântica dos impressos: conexões. Campinas, SP: Unicamp/IEL, 2014. Disponível em: http://issuu.com/marciaabreu/docs/circulacao_transatlantica_dos_impre; Acesso em: 20 de jan. 2016.
} 
não eram realizadas somente via Rio de Janeiro; envolviam também a ligação direta com a Europa, ${ }^{53}$ além de muitos dos livreiros e agentes das livrarias em Campinas serem estrangeiros, como Alexandre Pirret (francês), John Bryan (escocês) e Gaspar da Silva (português). Com exceção de A. L. Garraux - que foi objeto de estudos importantes, como o de Marisa Midori Deaecto ${ }^{54}$-, os outros nomes foram obscurecidos pela passagem do tempo. De fato, se a circulação dos livros for estudada sem atentar para seus mediadores, a visão do universo da difusão desses veículos literários fica incompleta.

Os nomes aqui mencionados - de agentes de livrarias, livreiros e de estabelecimentos que vendiam livros - desempenharam, em nosso entender, um papel importante para a circulação de impressos na Província de São Paulo e, por extensão, na disseminação de ideias. Portanto, conhecer as trajetórias desses homens pode contribuir para o conhecimento das redes sociais e comerciais que se efetivaram na Província de São Paulo, no que tange ao universo dos impressos. Atualmente, os nomes desses indivíduos e associações parecem não fazer qualquer sentido; contudo, participaram da dinâmica do comércio e da circulação de impressos na São Paulo provincial. ${ }^{55}$

Os livreiros e seus representantes/agentes foram considerados aqui segundo a perspectiva de Robert Darnton, que os vê como os "intermediários esquecidos", como o elo menos familiar do circuito do livro - ou seja, como o vínculo entre a produção e o consumo, entre o autor e o leitor. ${ }^{56}$ No universo heterogêneo dos intermediários do livro, o autor considera o livreiro o mediador mais significativo do ponto de vista da efetivação do processo de transmissão de ideias, pois opera na área crucial em que a oferta e a demanda se cruzam. Sob essa ótica, pode-se pensar que os anúncios dos jornais constituiriam algumas das formas de materializar a ligação entre livreiro e leitor

\footnotetext{
${ }^{53}$ Isso se deveu às inovações dos meios de transporte, que tornaram possível a inserção da capital paulista em um sistema mais amplo de comércio. Conforme Marisa Midori Deaecto: "O maior desafio da época, transpor a Serra do Mar com trilhos de ferro - superando, enfim, um obstáculo secular entre o porto de Santos e a capital - foi vencido pela Companhia Inglesa S. Paulo Railway. A importância desta linha não se mede apenas pela maior frequência de partidas em direção ao porto, mas também por tornar possível a ligação do burgo planaltino com o mercado internacional, sem a intermediação do Rio de Janeiro". DEAECTO, op. cit, p. 222 ( grifos nossos).

${ }^{54}$ Ibidem.

${ }^{55}$ Os nomes dos agentes de livrarias e de empresas jornalísticas, os quais foram encontrados na imprensa paulista da década de 1870, merecem uma pesquisa e uma análise à parte, que não seria possível realizar neste artigo, pois as trajetórias dos mediadores (Alexandre Pirret, Romão Vidal, John Bryan, Gaspar da Silva e M. Gomes de Almeida) podem ser uma chave importante para mostrar as conexões sociais e comerciais do universo dos impressos na província de São Paulo, durante o período enfocado.
}

${ }^{56}$ DARNTON, op. cit, p. 150 
(ou, ao menos, o leitor em potencial). E, se refletirmos acerca do que sugere Jean Marie Goulemot a respeito das bibliotecas - vistas como um espaço que realiza a missão de pôr fim "à dispersão dos saberes e à errância dos homens de cultura" ${ }^{57}$-, é possível afirmar que o livreiro e seus representantes (guardadas as devidas proporções) podem ser tomados como elementos altamente atuantes, que, por meio da propagação e distribuição de livros, retiravam as culturas de seu "lugar" e as aproximavam dos leitores, fossem eles efetivos ou potenciais.

Por fim, é importante registrar que, por meio dos jornais pesquisados para a elaboração deste artigo, foi possível mostrar algumas das práticas que integraram a história da divulgação e circulação de impressos na Província de São Paulo, no período focalizado. Embora tenha sido fornecida uma pequena amostra dos anúncios de livreiros, agentes de livrarias e de empresas jornalísticas, pertencentes a um universo muito mais amplo de títulos divulgados, é possível afirmar que a São Paulo provincial estava conectada com o universo dos negócios dos impressos além-mar e atualizada quanto ao repertório dos livros e jornais europeus.

Artigo recebido para publicação em 22/08/2016

Artigo aprovado para publicação em 03/11/2016

${ }^{57}$ GOULEMOT, Jean-Marie. O amor às bibliotecas. São Paulo: Edunesp, 2011. 